\title{
Calendar Spreads, Outright Futures Positions, and Risk
}

\author{
Ira G. Kawaller, Paul D. Koch, and Ludan LiU
}

IRA G. KAWALLER

is president of Kawaller \&

Co., LLC in Brooklyn,

NY.

kawaller@kawaller.com

Paul D. Koch

is the O. Maurice Joy

Professor of Finance at the

School of Business at the

University of Kansas in

Lawrence, KS.

pkoch@ku.edu

\section{LUDAN LIU}

is a Ph.D. candidate at the Carroll E. Wallace School of Management at Boston College in Chestnut Hill, MA.

ludan.liu@bc.edu
A futures calendar spread is constructed by simultaneously buying and selling two futures contracts with a common underlying instrument but different expiration dates-for instance, buying a December S\&P 500 futures contract and selling a September S\&P 500 contract. While spreads are generally considered to be less risky than outright futures positions, it is important to recognize that market participants typically trade a larger number of spreads than outrights. Presumably, such traders are attempting to achieve greater returns with similar risk, or similar returns with less risk. Depending on the relative sizes of the positions and the performance of the spreads vis-à-vis the outright, the goal of achieving similar returns or risk may or may not be realized.

These considerations raise several issues. For example, do these different trading approaches display similar performance (i.e., high or low correlations)? What are the relative risks of a calendar spread versus a single outright futures position? Are these risk characteristics stable over time? Given the relative risks, what are the appropriate capital (margin) requirements for trading spreads versus outright futures? Similarly, how many spreads should be traded to achieve comparable risk to a single outright futures position? Finally, what is the relative historical return performance of calendar spreads and outright futures positions with comparable risk?
We propose one way to determine the "appropriate" number of calendar spreads to trade relative to (or instead of) a single outright is to equalize the values-at-risk ( $\mathrm{VaR}$ ) of the two positions. If we assume that daily price changes in a single outright and a single calendar spread are both normally distributed, then the ratio of their respective standard deviations represents the multiple of spreads that offers a comparable VaR to a single outright, ex ante. We call this multiple the ex ante VaR-adjusted spread position. The ratio of standard deviations is appropriate to determine this multiple, however, only if the underlying distributions are normal. Because this assumption may not be valid, it is not clear which strategy would generate better ex post performance in terms of risk and return, or which would experience a return distribution with more desirable properties.

This study investigates these issues in a three-stage analysis, using daily data from 19911997 for 10 of the most active futures contracts traded in the U.S. The first-stage analysis compares the empirical distributions of daily price changes in a single outright futures contract versus a single calendar spread. We test the intertemporal stability of the standard deviations of these two respective positions, as well as the ratio of their standard deviations. This analysis sheds light on the relative return and risk of a single outright futures position versus a calendar spread, as well as possible difficulties in maintaining a VaR-adjusted spread position over time. 
In the second stage, we construct the VaR-adjusted spread position on a daily basis, and compare its ex post performance to that of a single outright. If this VaRadjustment truly equalizes risk, then the VaR-adjusted spread and the single outright position should presumably experience similar return performance over time. In making this comparison we focus on the mean, standard deviation, skewness, and kurtosis of each trading strategy, and we test both positions for departures from normality. The objective is to identify possible systematic differences between these ex post distributions that might be exploited. It is conceivable, for example, that the VaRadjusted spread could display an ex post distribution with similar average returns, but with a thinner left tail (less downward skewness or smaller kurtosis) than the single outright position. Such an outcome would imply that the $\mathrm{VaR}$-adjusted spread experiences less risk of great loss than the outright. ${ }^{1}$ This analysis reveals whether the VaRadjusted spread strategy in fact experiences similar return and/or risk to a single outright position, and illuminates any systematic discrepancies between the two approaches.

Third, we conduct simulations of a trading rule that stipulates buying or selling a single outright futures or a
VaR-adjusted spread position based on a moving average of past prices. We then compare the relative performances these trading strategies would have generated over the period 1995-1997. This final analysis sheds light on the relative risk and return offered by ex ante trading strategies involving a single outright futures or a VaR-adjusted calendar spread position.

When a trading strategy that operates on outright futures is compared to one that operates on calendar spreads, trade-offs pertaining to transactions costs versus capital requirements must be considered. Given that many more contracts are required by the spread trader in order to generate a similar dollar-return or bear comparable $\mathrm{VaR}$ to an outright futures trader, we might expect transactions costs for trading VaR-adjusted spreads to be considerably higher than those associated with trading a single outright. ${ }^{2}$ On the other hand, performance bond requirements for spread positions are often considerably smaller than for outright futures positions. This relative advantage of trading spreads is documented in Exhibit 1, which presents the initial margin requirements for trading a single outright futures versus a single calendar spread, for all 10 contracts investigated. The ratio of these two margin

\section{E X H I B I T 1}

\section{Initial Margin Requirements for One Outright Futures versus One Calendar Spread}

(1)

\begin{tabular}{lll}
\cline { 1 - 1 } Commodity & & Ticker \\
\cline { 1 - 1 } Crude oil & & $\mathrm{cl}$ \\
Corn & & $\mathrm{cn}$ \\
Deutschemark & $\mathrm{dm}$ \\
Eurodollar & & $\mathrm{ed}$ \\
Gold & & $\mathrm{gc}$ \\
Live cattle & & $\mathrm{lc}$ \\
Natural gas & & $\mathrm{ng}$ \\
S\&P 500 & & $\mathrm{sp}$ \\
Soybeans & & $\mathrm{sy}$ \\
U.S. bonds & & us
\end{tabular}

(3)

$\begin{array}{lrr}\text { Exchange }^{\mathbf{a}} & \text { Outright }^{\mathbf{b}} \\ \text { nym } & & \$ 1,620 \\ \text { cbot } & & \$ 540 \\ \text { cme } & & \$ 1,113 \\ \text { cme } & & \$ 675 \\ \text { cbot } & & \$ 1,080 \\ \text { cme } & & \$ 540 \\ \text { nym } & & \$ 3,375 \\ \text { cme } & & \$ 23,437 \\ \text { cbot } & & \$ 1,080 \\ \text { cbot } & & \$ 2,700\end{array}$

(5)

(6)

$\begin{array}{rrr}\text { Spread }^{\text {b }} & & (\mathbf{4}) /(\mathbf{5}) \\ \$ 1,000 & & 1.62 \\ \$ 400 & & 1.35 \\ \$ 300 & & 3.71 \\ \$ 300 & & 2.25 \\ \$ 300 & & 3.60 \\ \$ 500 & & 1.08 \\ \$ 600 & & 5.63 \\ \$ 1,000 & & 23.44 \\ \$ 800 & & 1.35 \\ \$ 400 & & 6.75\end{array}$

${ }^{a}$ nym $=$ New York Mercantile Exchange; cbot $=$ Chicago Board of Trade; cme = Chicago Mercantile Exchange.

b Sources: Websites for Chicago Board of Trade (www.cbot.com), Chicago Mercantile Exchange (www.cme.com), and Jack Carl's website (www.jackcarl.com/ margins.html).

For all cbot contracts documented above (cn, gc, sy, and us), the cbot website provides initial margin requirements for a single outright contract ("not hedging or spread-related"), and for hedging-related positions. The cme website provides initial margin and spread margin for its contracts, and Jack Carl's website provides initial and spread margins for all contracts. These performance bond requirements were in effect in December, 1999. 
requirements is provided in the last column in Exhibit 1, and represents the multiple of spreads that can be traded in each commodity with the same capital commitment as a single outright futures. It remains to be seen whether these relative advantages/disadvantages in terms of transactions costs and capital requirements are maintained after the values-at-risk are equalized for the two strategies. Our analysis takes these differences into consideration.

Results indicate that calendar spreads tend to bear more risk, in the form of higher kurtosis than outright futures, after adjusting the two positions for comparable values-at-risk. These relative risks should be taken into account by practitioners when trading spreads, and by exchanges when determining relative margin requirements.

The remainder of the article proceeds as follows. The next section provides background and motivation. The third section describes the data and methodology. This discussion is followed by our results and conclusions.

\section{BACKGROUND AND MOTIVATION}

\section{Background}

During the 1980s and 1990s the strong and sustained growth in U.S. equity prices dampened enthusiasm for alternative investments. However, the recent reversal in equity markets has generated a renewed desire for diversification into other areas.

One approach that has been striking a nerve with institutional investors is to allocate funds to a commodity trading advisor (CTA) or pool operator (CPO) who, in turn, divides these funds among a population of professional futures traders that specialize in various commodity markets. These practitioners rely on various futures trading strategies to actively manage their exposures to different commodity prices. The objective is for these traders to generate respectable rates of return that are largely uncorrelated with traditional portfolio holdings, thereby lowering the overall portfolio risk without significantly altering the expected return (Brorsen and Lukac [1990], Edwards and Liew [1999], and Schneeweis et al. [1996]). For example, many professional futures traders follow a disciplined approach of diversifying across a broad array of asset markets driven by different sectors of the world economy that are relatively insensitive to one another over time.

As a complement or alternative to diversification, many professional futures traders attempt to enhance returns by operating with rigorous trading discipline, for example, by ensuring that losses are constrained on unprof- itable trades. For many traders the source of this discipline is reliance on an objective trading rule designed to terminate positions on losing trades while allowing profitable trades to remain in effect. The concept, at least, is quite simple; if you win on half of your trades and lose on half, you still gain if the amount associated with winners exceeds that associated with losers.

Generally, these objective trading systems fall under one of two approaches: trend-following or mean-reverting. In trend-following schemes traders develop a systematic, objective rule for discerning the evolution of a trend, which they then use to signal the likelihood of a profitable opportunity. When the objective criteria implied by the rule are met the trade is initiated and, as long as the criteria are maintained, the trade stays in place. In mean-reverting approaches, the rule is designed to determine when prices have "gone too far," and some adjustment is expected back to a "more normal value." 3

\section{Futures Calendar Spreads}

An alternative to trading futures contracts outright is a strategy that speculates on relative futures price movements, by simultaneously buying and selling related futures. One common construct that satisfies this objective is the futures calendar spread. A market-neutral calendar spread employs two offsetting futures contracts (i.e., one long and one short) having the same underlying instrument but different expirations. ${ }^{4}$ For example, a trader can sell a short-term futures such as the nearby (next-to-expire) contract, and simultaneously buy a longer-term futures such as the next out (second-to-expire) contract on the same underlying commodity. For consistency with prior work, we define the value of a long position in this calendar spread as $\left(\mathrm{F}_{2}-\mathrm{F}_{1}\right)$, where $\mathrm{F}_{1}$ is the price of the nearby contract and $\mathrm{F}_{2}$ is the price of the next out contract. This position will increase (decrease) in value if the spread between the two futures prices rises (falls).

In some cases, spread prices $\left(\mathrm{F}_{2}-\mathrm{F}_{1}\right)$ are highly correlated with outright futures prices $\left(\mathrm{F}_{1}\right.$ or $\left.\mathrm{F}_{2}\right)$, and traders might therefore use calendar spreads as a less risky surrogate for outright futures positions. In other cases, however, calendar spread prices exhibit low correlations with outright futures prices. Under these circumstances traders might use calendar spreads as a complement to outright positions to diversify portfolio risk. 


\section{Comparison of Risk and Return}

Comparison of the risk and return performance of outright futures versus calendar spread positions requires that we clarify what is meant by "risk." One important aspect of risk is captured by the standard deviation of price changes. Other critical attributes of risk focus on the behavior of the tails of the distribution, and thereby reflect the best and worst possible outcomes associated with an investment. These other attributes are embodied in higherorder moments of the distribution of price changes, and include skewness and kurtosis. A normal distribution displays unique behavior with regard to the tails (no skewness and kurtosis $=3$ ). Departures from normality might include, for example, downward skewness and thicker tails (higher kurtosis), which would both mean a higher probability of great loss than is implied by the normal distribution. ${ }^{5}$

Value-at-risk $(\mathrm{VaR})$ technology offers an alternative measure of risk exposure that focuses on the left tail of the distribution. The $\mathrm{VaR}$ of a position is simply a measure of the maximum amount one would expect to lose over a certain period with a given level of confidence, assuming the underlying distribution of price changes is normal (Hull [2002]; Jorion [1997]).

If we assume that daily price changes in both outright futures and calendar spread positions $\left(\Delta \mathrm{F}_{1}\right.$ and $\left.\Delta\left(\mathrm{F}_{2}-\mathrm{F}_{1}\right)\right)$ follow stable normal distributions, it is a straightforward exercise to determine the number of calendar spreads that offers a comparable VaR to a single outright position, ex ante. In this regard we define $\sigma_{\Delta \mathrm{F} 1}$ as the standard deviation of daily price changes in one outright position, and $\sigma_{\Delta(\mathrm{F} 2-\mathrm{F} 1)}$ as the standard deviation of daily price changes in one spread. The ratio, $\left(\sigma_{\Delta \mathrm{F} 1} / \sigma_{\Delta(\mathrm{F} 2-\mathrm{F} 1)}\right)$, then gives the appropriate multiple of spreads to outrights that yields equal VaR, ex ante. We call this multiple the ex ante VaRadjusted spread position.

\section{Complications}

Under the normality assumption for both $\Delta \mathrm{F}_{1}$ and $\Delta\left(\mathrm{F}_{2}-\mathrm{F}_{1}\right)$, the VaR-adjusted spread and a single outright would have the same expected maximum loss on any given day, for any given degree of confidence. However, ex post, these two strategies might experience divergent results, due to: 1) inherent instability associated with maintaining the VaR-adjusted spread, or 2) departures from normality in the futures or spread price change series. Consider each complication in turn.

First, the relative volatilities of these two positions,
$\left(\sigma_{\Delta \mathrm{F} 1} / \sigma_{\Delta(\mathrm{F} 2-\mathrm{F} 1)}\right)$, may change over time. Since a single outright futures contract is the benchmark portfolio, the VaRadjusted spread must be rebalanced periodically to maintain the same ex ante $\mathrm{VaR}$ as a single outright at any point in time. As the ratio of standard deviations changes, periodic rebalancing of the VaR-adjusted spread represents an attempt to continually "hit a moving target." Moreover, the VaR-adjusted spread will vary over time because each successive computation of relative standard deviations is only a point estimate of the true ratio. This implies that periodic rebalancing represents a source of inherent instability in the VaR-adjusted spread relative to a single outright. ${ }^{6}$

Second, under the joint assumption that daily changes in outright futures prices $(\Delta \mathrm{F} 1)$ and spread prices $(\Delta(\mathrm{F} 2-\mathrm{F} 1))$ are both normally distributed, their respective standard deviations are sufficient to characterize VaR. However, these two assumptions may not be jointly compatible. For example, it is common to assume that daily futures price levels are lognormal so that futures returns are normal. In this case, however, the spread price level would be the difference in two lognormals, which unfortunately is no longer lognormal (Poitras [1998]). Furthermore, we are interested in daily changes in the levels of both the futures and spread price series, rather than daily returns. ${ }^{7}$ Under the lognormal assumption for outright futures price levels, the daily change in the outright price is also the difference in two lognormals, while the daily change in the spread price is the difference of the difference in two lognormals. In this case neither price change series is well behaved.

In light of the growing body of evidence suggesting that futures price levels are not lognormal (see, e.g., Cornew et al. [1984] and Hudson et al. [1987]), some researchers explicitly assume that spread price changes are normally distributed, and then investigate the validity of this assumption. For example, Kim and Leuthold [1997] and Poitras [1990] document that daily price changes in futures calendar spreads experience significant departures from normality, in the form of both skewness and kurtosis. They suggest these departures may be due to the relatively small price changes that normally occur over daily intervals, and they demonstrate that lengthening the interval to consider weekly price changes results in fewer departures from normality. Kim and Leuthold [1997] then go further to determine the best-fitting distributions of spread price changes. While the distribution of futures spread price changes is close to normal (the normal is typically either the best or second best empirical distribution describing spread price behavior out of the 25 distributions investigated), they find 
the logistic distribution often fits the data better than the normal. On the other hand, their results are sensitive to the underlying commodity, sample period, sample size, and spread length, as well as the differencing interval, making it difficult to generalize their results.

While prior evidence is mixed, the possibility that futures and spread price changes are non-normal complicates our application of VaR technology. The analytical problem has to do with the methodology for determining VaR when the underlying true distribution is non-Gaussian. There are several ways to deal with this problem. Some are computationally cheap and some are not. They are all non-parametric and thus run the risk of efficiency loss in estimation. It is therefore safe to say that these methods might not improve upon the (possibly misspecified) Gaussian approach. ${ }^{8}$

While these alternative procedures hold promise for future research, we adhere to the simple approach of most previous work on these issues by assuming that outright and spread price changes are normal. We then investigate the validity of this assumption. The ultimate focus in this study is whether the ex post assessment of risk associated with VaR-adjusted spreads differs in any systematic way from the ex post risk of a single outright futures position.

\section{DATA AND METHODOLOGY}

This study uses daily data from 1991-1997, for 10 of the most active futures contracts traded in U.S. markets: crude oil, corn, Deutschemarks, Eurodollars, gold, live cattle, natural gas, the S\&P 500, soybeans, and U.S. government bonds. The analysis proceeds in three stages.

First, for each contract we assess the nature and stability of the means, standard deviations, and correlation between daily changes in the value of one outright contract and one calendar spread position: $\left(\mu_{\Delta \mathrm{F} 1}, \sigma_{\Delta \mathrm{F} 1}\right)$, $\left(\mu_{\Delta(\mathrm{F} 2-\mathrm{F} 1)}, \sigma_{\Delta(\mathrm{F} 2-\mathrm{F} 1)}\right)$, and $\rho_{\Delta \mathrm{F} 1, \Delta(\mathrm{F} 2-\mathrm{F} 1)}$. In this analysis we wish to avoid potentially aberrant behavior associated with illiquid futures markets, or with expiration-related trading strategies. To deal with the former concern, we limit our attention to the most liquid nearby outright futures contract, and the spread position between the nearby and next out contracts. To deal with the latter concern, we roll over to the next contract maturity/maturities on the first day of the month in which the nearby contract expires. Thus, for purposes of this analysis, one contract period extends from the first day of one expiration month until the first day of the next expiration month. For each commodity contract, the analysis is performed for all nearby contract periods that expire between 1991 and $1997 .{ }^{9}$ We then aggregate results across all contract periods that expire during every calendar year, and we summarize annual results for the years 1991-1997, as well as over the entire seven-year period. Finally, we assess the stability of each standard deviation, as well as the ratio of standard deviations $\left(\sigma_{\Delta \mathrm{F} 1}, \sigma_{\Delta(\mathrm{F} 2-\mathrm{F} 1)}\right.$, and $\left.\sigma_{\Delta \mathrm{F} 1} / \sigma_{\Delta(\mathrm{F} 2-\mathrm{F} 1)}\right)$ across consecutive time periods. This first-stage analysis therefore sheds light on the nature and stability of return, risk, and co-movement in price changes for a single outright position versus a single calendar spread.

Second, the ex ante VaR-adjusted spread position is constructed for all business days over each contract period. Beginning on the first day of expiration month, the standard deviation of daily price changes is estimated for one outright contract and for one spread position, respectively, using data over the prior 60 trading days. The ratio of these two standard deviations determines the number of calendar spreads to hold on that day for the VaR-adjusted spread position. The VaR-adjusted spread is then rebalanced (i.e., the ratio of standard deviations is recomputed) weekly over each contract period. The ex post daily performance of this ex ante $\mathrm{VaR}$-adjusted spread strategy is then examined for all contract periods over the years 1991-1997. Various aspects of the risk and return for this VaR-adjusted spread are then compared to those of the single outright position.

Third, a simulation is conducted that applies a naive trading rule for each strategy - first to a single outright position and then to the VaR-adjusted spread. These rules simply compel entering a long position in one outright contract when a 20-day moving average of past outright futures prices rises, and entering a short position when the moving average declines. Analogous rules employing a 20-day moving average are also prescribed in connection with trading calendar spreads. ${ }^{10}$ The simulations cover every business day over the years 1995-1997. This final analysis pursues an alternative avenue to reveal, once again, whether the proposed VaR-adjusted spread strategy could have been used to achieve a similar level of performance to one outright futures position, in terms of return, standard deviation, skewness, and kurtosis. ${ }^{11}$

\section{EMPIRICAL RESULTS}

\section{Ex Post Distribution for One Outright versus One Spread Position}

Exhibit 2 provides the means, standard deviations, and correlations between daily price changes in a single 
outright and a single spread position, for all 10 contracts investigated. Results are summarized for annual subsamples from 1991 to 1997, as well as over the entire sample period.

First consider the correlations between outright and spread price levels and price changes, respectively, presented in columns 6 and 7 of Exhibit 2. For many contracts these correlations are small in magnitude, and they vary substantially across periods considered and contracts examined. ${ }^{12}$ These results indicate that the calendar spread does not generally serve well as a surrogate for trading outrights. Instead, the low and unstable correlations documented in Exhibit 2 suggest that including spreads in a portfolio could provide risk-reduction benefits associated with diversification.

Second, consider the mean and standard deviation of daily price changes in a single outright versus a single spread, listed in columns 1 through 4 of Exhibit 2. As expected, for all 10 contracts, the mean or standard deviation of a single outright futures contract typically represents a substantial multiple over the analogous mean or standard deviation associated with a single spread position.

The ratio of standard deviations provided in column 5 of Exhibit 2 indicates the relative risk associated with a single outright versus a single calendar spread, for every contract examined. This ratio of volatilities represents the multiple used to generate the VaR-adjusted spread position, averaged over all contract periods within each annual subsample. It is noteworthy that, for most contracts, this volatility ratio is substantially greater than the analogous ratio of margin requirements documented in Exhibit 1. For example, for U.S. bonds the ratio of margin requirements (outright margins divided by spread margins) presented in Exhibit 1 is 6.75, while the analogous ratio of standard deviations provided in Exhibit 2 ranges from 23 to 42 for all annual subsamples. These results suggest that relative margin requirements are often out of line with the relative risks posed by each trading strategy. Specifically, margin requirements are generally too high for spreads, or too low for outrights, in relation to their relative volatilities. This generalization holds for all but two commodities: the Eurodollar contract exhibits a ratio of standard deviations that is roughly comparable to the relative margin requirements for the two positions; natural gas, on the other hand, has experienced a volatility ratio that is consistently less than the ratio of margin requirements.

Finally, consider the stability of volatility over time. For some contracts these standard deviations and their ratio appear fairly stable, while for other contracts there is much variation across years. In this light we formally test three respective null hypotheses for each contract investigated, that the three variables $\sigma_{\Delta \mathrm{F} 1}, \sigma_{\Delta(\mathrm{F} 2-\mathrm{F} 1)}$, and $\left(\sigma_{\Delta \mathrm{F} 1} / \sigma_{\Delta(\mathrm{F} 2-\mathrm{F} 1)}\right)$ are stable across consecutive periods. Exhibit 3 provides the relative frequencies of rejecting these three null hypotheses, at various levels of statistical significance. The relative frequencies in each column of Exhibit 3 are uniformly greater than the approximate marginal significance level heading that column. These results indicate substantive instability in both standard deviations, as well as their ratio, suggesting that maintenance of a VaR-adjusted spread position is likely to require substantial rebalancing over time, for all 10 contracts examined.

\section{Ex Post Distribution for One Outright versus VaR-Adjusted Spread}

Exhibit 4 presents evidence regarding the ex post performance of one outright futures contract and the VaR-adjusted spread, for all 10 contracts investigated. Annual summary statistics are provided for the mean, standard deviation, skewness, and kurtosis. Consider each statistic, in turn.

First, for most of the 10 contracts analyzed, mean daily changes in the outright futures and VaR-adjusted spread positions are roughly similar in magnitude. Over the entire seven-year sample period, the outright futures have slightly higher mean daily price changes for five contracts, the VaR-adjusted spreads have higher means for four contracts, and one contract reveals identical mean price changes for the two positions. This result is in keeping with expectations. That is, given the objective of constructing positions with equal value-at-risk, returns for VaR-adjusted spreads should not show systematic differences from returns on single outright positions.

Second, consider the relative standard deviations of the two positions. Despite the ex ante equivalence of their standard deviations, for virtually all annual subsamples the single outright displays a smaller ex post standard deviation than the VaR-adjusted spread [i.e., volatility of outright $\left(\sigma_{\Delta \mathrm{F} 1}\right)_{\mathrm{t}}<$ volatility of $\mathrm{VaR}$-adjusted spread $\left(\sigma_{\Delta(\mathrm{F} 2-\mathrm{F} 1)}\right)_{\mathrm{t}} \cdot{ }^{\Delta 3}$ For some contracts this difference is substantial. Thus, while the two positions tend to experience similar mean daily price changes over time, the VaR-adjusted spread does so with consistently greater volatility. This result may justify the seemingly high initial margin requirements for calendar spreads, when based on the ex ante volatility ratios. It also calls into question the validity of the normality assumption, and leads us to 


\section{E X H I B I T 2}

Summary Statistics for One Outright versus One Calendar Spread

Outright Spread

\begin{tabular}{|c|c|c|c|c|c|c|c|c|}
\hline & $\begin{array}{r}\operatorname{col}(1) \\
\mu_{\Delta \mathrm{F} 1}\end{array}$ & $\begin{array}{r}\operatorname{col}(2) \\
\sigma_{\Delta \mathrm{F} 1}\end{array}$ & $\begin{array}{c}\operatorname{col}(3) \\
\mu_{\Delta(\mathrm{F} 2-\mathrm{F} 1)}\end{array}$ & $\begin{array}{r}\operatorname{col}(4) \\
\sigma_{\Delta(\mathrm{F} 2-\mathrm{F} 1)}\end{array}$ & $\begin{array}{l}\operatorname{col}(5) \\
(2) /(4)\end{array}$ & $\begin{array}{r}\operatorname{col}(6) \\
\rho_{\mathrm{F} 1,(\mathrm{~F} 2-\mathrm{F} 1)}\end{array}$ & $\begin{array}{r}\operatorname{col}(7) \\
\rho_{\Delta \mathrm{F} 1, \Delta(\mathrm{F} 2-\mathrm{Fl})} \\
\end{array}$ & $\begin{array}{r}\operatorname{col}(8) \\
\% \text { bkwd } \\
\end{array}$ \\
\hline \multicolumn{9}{|c|}{ Crude Oil (cl) } \\
\hline 1991 & -.040 & .66 & .0190 & .170 & 3.86 & -.64 & -.76 & 87.3 \\
\hline 1992 & -.010 & .25 & .0021 & .027 & 9.32 & -.85 & -.64 & 60.1 \\
\hline 1993 & -.022 & .23 & .0035 & .024 & 9.67 & -.76 & -.65 & 1.2 \\
\hline 1994 & .008 & .29 & -.0047 & .038 & 7.51 & -.76 & -.71 & 37.5 \\
\hline 1995 & .007 & .21 & -.0027 & .034 & 6.22 & -.63 & -.69 & 89.6 \\
\hline 1996 & .054 & .36 & -.0091 & .077 & 4.62 & -.41 & -.81 & 100.0 \\
\hline 1997 & -.003 & .37 & .0032 & .041 & 8.91 & -.95 & -.70 & 52.4 \\
\hline $91-97$ & -.001 & .34 & .0016 & .059 & 5.74 & -.57 & -.71 & 61.2 \\
\hline \multicolumn{9}{|c|}{ Corn (cn) } \\
\hline 1991 & -.09 & 2.70 & .036 & .57 & 4.72 & .16 & .05 & 13.5 \\
\hline 1992 & -.27 & 2.45 & .008 & .48 & 5.10 & -.36 & .06 & 4.4 \\
\hline 1993 & .10 & 2.13 & -.012 & .41 & 5.19 & .14 & -.09 & 0 \\
\hline 1994 & -.37 & 2.97 & .046 & .61 & 4.90 & -.37 & -.07 & 21.4 \\
\hline 1995 & .35 & 2.35 & -.006 & .43 & 5.50 & -.20 & .08 & 9.5 \\
\hline 1996 & .48 & 6.51 & -.130 & 3.34 & 1.95 & -.78 & -.51 & 51.8 \\
\hline 1997 & .00 & 3.82 & .018 & .78 & 4.90 & -.04 & -.14 & 33.3 \\
\hline $91-97$ & .03 & 3.28 & -.006 & .95 & 3.47 & -.73 & -.34 & 19.1 \\
\hline \multicolumn{9}{|c|}{ Deutschemark (dm) } \\
\hline 1991 & -.00015 & .0053 & -.000023 & .00012 & 44.19 & .26 & -.38 & 100.0 \\
\hline 1992 & .00018 & .0053 & -.000016 & .00018 & 30.39 & -.80 & -.65 & 100.0 \\
\hline 1993 & -.00008 & .0043 & -.000010 & .00010 & 42.17 & -.55 & -.44 & 100.0 \\
\hline 1994 & .00024 & .0037 & .000005 & .00009 & 38.90 & .92 & .09 & 46.5 \\
\hline 1995 & .00019 & .0054 & .000004 & .00011 & 49.52 & .06 & .32 & 0 \\
\hline 1996 & -.00021 & .0028 & -.000002 & .00007 & 42.28 & -.59 & .05 & 0 \\
\hline 1997 & -.00039 & .0036 & -.000006 & .00005 & 73.41 & .54 & .22 & 0 \\
\hline $91-97$ & -.00003 & .0043 & -.000007 & .00010 & 43.47 & .27 & -.23 & 49.5 \\
\hline \multicolumn{9}{|c|}{ Eurodollar (ed) } \\
\hline 1991 & .0130 & .055 & .0010 & .024 & 2.32 & .06 & .20 & 52.0 \\
\hline 1992 & .0054 & .061 & .0019 & .026 & 2.33 & .40 & .47 & 91.3 \\
\hline 1993 & .0045 & .033 & .0019 & .023 & 1.47 & .38 & .65 & 96.4 \\
\hline 1994 & -.0037 & .045 & -.0037 & .024 & 1.89 & .45 & .52 & 100.0 \\
\hline 1995 & .0045 & .049 & .0041 & .032 & 1.55 & .91 & .58 & 48.6 \\
\hline 1996 & .0011 & .030 & -.0001 & .012 & 2.51 & 67 & .25 & 56.3 \\
\hline 1997 & .0001 & .018 & .0004 & .009 & 2.03 & .19 & .21 & 90.8 \\
\hline $91-97$ & .0025 & .035 & .0006 & 017 & 2.07 & -.12 & .45 & 76.5 \\
\hline \multicolumn{9}{|c|}{ Gold $(\mathrm{gc})$} \\
\hline 1991 & -.14 & 2.76 & -.004 & .09 & 29.23 & .33 & .37 & 0 \\
\hline 1992 & -.19 & 1.85 & -.006 & .07 & 26.40 & .57 & -.06 & 0 \\
\hline 1993 & .11 & 2.97 & .004 & .05 & 57.97 & .90 & .29 & 0 \\
\hline 1994 & -.03 & 2.34 & .008 & .05 & 44.80 & .21 & .15 & 0 \\
\hline 1995 & -.03 & 1.53 & -.040 & .19 & 8.12 & -.19 & .16 & 0 \\
\hline 1996 & -.12 & 1.37 & -.015 & .14 & 9.93 & .23 & .01 & 0 \\
\hline 1997 & -.33 & 2.31 & -.034 & .14 & 16.56 & .07 & .15 & 0 \\
\hline $91-97$ & -.12 & 2.04 & -.017 & .12 & 17.19 & . 27 & .12 & 0 \\
\hline
\end{tabular}


E X H I B I T 2 (continued)

Summary Statistics for One Outright versus One Calendar Spread

\begin{tabular}{|c|c|c|c|c|c|c|c|c|}
\hline & $\mu_{\Delta \mathrm{F} 1}$ & $\sigma_{\Delta \mathrm{F} 1}$ & $\mu_{\Delta(\mathrm{F} 2-\mathrm{F} 1)}$ & $\sigma_{\Delta(\mathrm{F} 2-\mathrm{F} 1)}$ & $(2) /(4)$ & $\rho_{\mathrm{F} 1,(\mathrm{~F} 2-\mathrm{F} 1)}$ & $\rho_{\Delta} \mathrm{F} 1, \Delta(\mathrm{F} 2-\mathrm{F} 1)$ & \%bkwd \\
\hline \multicolumn{9}{|c|}{ Live Cattle (lc) } \\
\hline 1991 & .006 & .46 & .006 & .21 & 2.18 & -.91 & -.51 & 54.4 \\
\hline 1992 & .040 & .48 & .012 & .21 & 2.24 & -.62 & -.56 & 79.1 \\
\hline 1993 & .021 & .48 & -.003 & .22 & 2.13 & -.85 & -.60 & 53.4 \\
\hline 1994 & -.034 & .58 & .013 & .24 & 2.42 & -.52 & -.59 & 62.9 \\
\hline 1995 & .015 & .56 & .007 & .26 & 2.13 & -.50 & -.72 & 49.4 \\
\hline 1996 & -.002 & .59 & .014 & .30 & 2.00 & -.73 & -.62 & 53.0 \\
\hline 1997 & .011 & .50 & -.017 & .26 & 1.89 & -.35 & -.55 & 27.0 \\
\hline $91-97$ & .008 & .52 & .004 & .24 & 2.13 & -.48 & -.60 & 54.2 \\
\hline \multicolumn{9}{|c|}{ Natural Gas (ng) } \\
\hline 1991 & -.0038 & .023 & .0018 & .011 & 2.02 & -.41 & $\begin{array}{l}-.61 \\
\end{array}$ & 28.2 \\
\hline 1992 & .0025 & .036 & -.0011 & .013 & 2.77 & -.21 & -.67 & 51.8 \\
\hline 1993 & .0013 & .042 & -.0005 & .014 & 3.01 & .21 & -.69 & 45.4 \\
\hline 1994 & -.0030 & .038 & .0012 & .013 & 2.89 & -.88 & -.83 & 42.2 \\
\hline 1995 & -.0032 & .035 & .0009 & .011 & 3.27 & -.26 & -.66 & 8.0 \\
\hline 1996 & .0067 & .069 & -.0021 & .029 & 2.39 & -.30 & -.84 & 70.6 \\
\hline 1997 & .0048 & .087 & .0001 & .029 & 3.01 & -.60 & -.82 & 55.3 \\
\hline $91-97$ & .0007 & .047 & .0001 & .017 & 2.76 & -.43 & -.79 & 42.9 \\
\hline \multicolumn{9}{|c|}{ S\&P 500 (sp) } \\
\hline 1991 & .16 & 3.35 & -.0024 & .080 & 42.00 & -.25 & .38 & 0 \\
\hline 1992 & .20 & 2.76 & -.0025 & .077 & 35.64 & -.31 & .25 & 0.8 \\
\hline 1993 & .11 & 2.47 & .0009 & .060 & 41.33 & .66 & .12 & 0 \\
\hline 1994 & -.06 & 2.98 & .0028 & .067 & 44.48 & -.26 & .09 & 0 \\
\hline 1995 & .54 & 2.76 & .0072 & .066 & 41.64 & .61 & .07 & 0 \\
\hline 1996 & .51 & 5.16 & .0094 & .100 & 51.17 & .85 & .27 & 0 \\
\hline 1997 & .65 & 10.76 & .0097 & .140 & 79.59 & .97 & .45 & 0 \\
\hline $91-97$ & .30 & 4.32 & .0036 & .084 & 51.44 & .92 & .32 & 0.1 \\
\hline \multicolumn{9}{|c|}{ Soybeans (sy) } \\
\hline 1991 & -.25 & 8.29 & .018 & .95 & 8.75 & .44 & -.05 & 3.2 \\
\hline 1992 & -.26 & 5.31 & -.120 & .85 & 6.27 & .14 & .02 & 8.8 \\
\hline 1993 & .19 & 6.56 & .013 & .77 & 8.54 & -.24 & .07 & 15.5 \\
\hline 1994 & -.50 & 7.43 & .043 & .99 & 7.50 & .00 & -.07 & 40.1 \\
\hline 1995 & .32 & 5.86 & .016 & .51 & 11.42 & -.08 & .02 & 0 \\
\hline 1996 & .20 & 9.49 & -.075 & 1.19 & 7.94 & -.48 & -.24 & 32.7 \\
\hline 1997 & .77 & 10.78 & -.240 & 2.56 & 4.22 & -.15 & -.36 & 56.1 \\
\hline $91-97$ & .07 & 7.68 & -.049 & 1.12 & 6.87 & -.42 & -.19 & 22.3 \\
\hline \multicolumn{9}{|c|}{ U.S. Treasury Bond (us) } \\
\hline 1991 & .029 & .52 & -.0027 & .021 & 24.76 & -.36 & -.15 & 100 \\
\hline 1992 & .030 & .50 & -.0012 & .021 & 23.74 & -.65 & -.25 & 100 \\
\hline 1993 & .069 & .56 & -.0011 & .023 & 24.47 & .02 & -.10 & 100 \\
\hline 1994 & -.050 & .68 & -.0005 & .020 & 33.97 & -.89 & -.15 & 100 \\
\hline 1995 & .091 & .59 & .0011 & .019 & 30.14 & .42 & -.00 & 100 \\
\hline 1996 & -.057 & .72 & -.0002 & .017 & 41.90 & .68 & -.03 & 100 \\
\hline 1997 & .048 & .53 & .0009 & .017 & 32.11 & .54 & .09 & 100 \\
\hline 91-97 & .026 & .58 & -.0006 & .020 & 29.27 & .12 & -.09 & 100 \\
\hline
\end{tabular}

Columns (1) and (2) provide the mean and standard deviation of daily price changes in one outright futures contract, averaged over all contract periods that expire within each calendar year. Columns (3) and (4) provide the mean and standard deviation of daily price changes in one calendar spread position, averaged over all contract periods that expire within each calendar year. Column (5) displays the ratio of standard deviations for each subsample that determines the VaR-adjusted spread. Columns (6) and (7) give the correlation between daily outright and spread price levels, and price changes, respectively. Column (8) presents the percent of days during each subsample that the forward curve is backwardated $\left(\left(F_{2}-F_{1}\right)<0\right)$. 


\section{E X H I B I T 3 \\ Stability of Volatility for Outright, for Spread, and Volatility Ratio}

$\begin{array}{ll}\text { Outright: } & \mathrm{H}_{1}: \sigma\left(\Delta \mathrm{F}_{1}\right) \text { in Period } 1=\sigma\left(\Delta \mathrm{F}_{1}\right) \text { in Period } 2 \\ \text { Spread: } & \mathrm{H}_{2}: \sigma\left(\Delta\left(\mathrm{F}_{2}-\mathrm{F}_{1}\right)\right) \text { in Period } 1=\sigma\left(\Delta\left(\mathrm{F}_{2}-\mathrm{F}_{1}\right)\right) \text { in Period } 2 \\ \text { Ratio: } & \mathrm{H}_{3}: \sigma\left(\Delta \mathrm{F}_{1}\right) / \sigma\left(\Delta\left(\mathrm{F}_{2}-\mathrm{F}_{1}\right)\right) \text { on Day } 1=\sigma\left(\Delta \mathrm{F}_{1}\right) / \sigma\left(\Delta\left(\mathrm{F}_{2}-\mathrm{F}_{1}\right)\right) \text { on Day } 2\end{array}$

These results represent the relative frequencies of rejecting each null hypothesis at the $.10, .05$, and .01 levels of significance, respectively, for all contract periods between 1991 and 1997.

\begin{tabular}{|c|c|c|c|c|c|c|c|c|c|c|}
\hline contract & $\begin{array}{l}\text { \# of } \\
\text { Tests }\end{array}$ & \multicolumn{3}{|c|}{$\begin{array}{c}\text { relative frequency } \\
\text { of rejecting } \mathrm{H}_{1} \\
\text { (level of significance) }\end{array}$} & \multicolumn{3}{|c|}{$\begin{array}{c}\text { relative frequency } \\
\text { of rejecting } \mathrm{H}_{2} \\
\text { (level of significance) }\end{array}$} & \multicolumn{3}{|c|}{$\begin{array}{c}\text { relative frequency } \\
\text { of rejecting } \mathrm{H}_{3} \\
\text { (level of significance) }\end{array}$} \\
\hline crude oil (cl) & 83 & .22 & .13 & .08 & .24 & .18 & .04 & .83 & .81 & .73 \\
\hline corn $(\mathrm{cn})$ & 35 & .63 & .49 & .40 & .60 & .60 & .54 & .97 & .97 & .94 \\
\hline Deutschemarks (dm) & 27 & .43 & .29 & .18 & .29 & .18 & .14 & .86 & .71 & .71 \\
\hline Eurodollar (ed) & 43 & .64 & .57 & .45 & .57 & .43 & .27 & .86 & .86 & .84 \\
\hline gold (gc) & 59 & .42 & .39 & .32 & .59 & .56 & .49 & .85 & .80 & .73 \\
\hline live cattle (lc) & 41 & .24 & .17 & .07 & .24 & .10 & .07 & .88 & .86 & .83 \\
\hline natural gas (ng) & 83 & .26 & .13 & .10 & .50 & .45 & .28 & .88 & .87 & .79 \\
\hline S\&P 500 (sp) & 27 & .43 & .29 & .18 & .29 & .18 & .14 & .93 & .93 & .89 \\
\hline soybeans (sy) & 47 & .46 & .35 & .29 & .50 & .48 & .25 & .94 & .92 & .90 \\
\hline U.S. bonds (us) & 27 & .41 & .26 & .11 & .52 & .44 & .30 & .93 & .93 & .93 \\
\hline
\end{tabular}

For $\mathrm{H}_{1}$ and $\mathrm{H}_{2}$ :

$\sigma\left(\Delta F_{1}\right)=$ standard deviation of daily changes in $F_{1}$ computed over a single contract period;

$\sigma\left(\Delta\left(F_{2}-F_{1}\right)\right)=$ standard deviation of daily changes in $\left(F_{2}-F_{1}\right)$ computed over a single contract period. We assume contracts are rolled over the first day of expiration month. Thus, each contract period extends from the first day of one expiration month to the first day of the next expiration month.

$H_{1}$ is the null hypothesis that the standard deviation of daily changes in $F_{1}$ is stable from one contract period to next. $H_{2}$ is the null hypothesis that the standard deviation of daily changes in $\left(F_{2}-F_{1}\right)$ is stable from one contract period to next. These two hypotheses are tested for each pair of consecutive contract periods using the Variance Ratio Test. The Modified Levene Test was also conducted with generally robust results. For $H_{1}$ and $H_{2}$, the number of tests in each row is the number of contract periods less one, and ranges from 27 tests for contracts expiring quarterly over seven years, to 83 tests for contracts expiring monthly. Some contracts have eight expirations per year, and some switch from quarterly to monthly contract periods during the 1991-97 sample period.

For $H_{3}$, the ratio, $\sigma\left(\Delta F_{1}\right) / \sigma\left(\Delta\left(F_{2}-F_{1}\right)\right)$, is recomputed on a daily basis, using the standard deviations of the series, $\Delta F_{1}$ and $\Delta\left(F_{2}-F_{1}\right)$, respectively, computed over the previous 60 days.

$\mathrm{H}_{3}$ is the null hypothesis that this volatility ratio is stable from one day to the next, during each contract period. $\mathrm{H}_{3}$ is tested with the mean difference $t$-test of this ratio on Day $n$ relative to Day $n-1$, across all days each period. For $\mathrm{H}_{3}$, there is one test for every contract period.

concentrate on the relative skewness and kurtosis experienced by these two positions.

Skewness tends to be small in magnitude and similar for both the single outright futures and the VaRadjusted spread positions, for all but one contract (the S\&P 500) ${ }^{14}$ Given this general lack of skewness, we focus on the relative degrees of kurtosis experienced by the outright futures and the VaR-adjusted spread positions, respectively. The larger standard deviations experienced by the VaR-adjusted spread for all 10 contracts suggest a likely tendency for greater kurtosis in the VaR-adjusted spread position, relative to the outright futures position.
The question remains, to what extent is kurtosis greater for the VaR-adjusted spread position across these 10 contracts.

Exhibit 4 indicates that, over the entire sample period, the outright position experiences greater kurtosis than the VaR-adjusted spread for only one contract (Eurodollars). In all other cases the VaR-adjusted spread tends to have greater kurtosis. For five contracts, the difference in kurtosis is relatively minor (crude oil, corn, live cattle, natural gas, and soybeans). For the remaining four contracts (Deutschemarks, gold, S\&P 500, and U.S. bonds), however, the difference is substantial, with the 


\section{E X H I B I T 4}

Distributional Properties for One Outright versus VaR-Adjusted Calendar Spread

\begin{tabular}{|c|c|c|c|c|c|c|c|c|}
\hline \multicolumn{5}{|c|}{ Outright } & \multicolumn{4}{|c|}{ VaR-Adjusted Spread } \\
\hline & $\operatorname{Col}(1)$ & $\operatorname{Col}(2)$ & $\operatorname{Col}(3)$ & $\operatorname{Col}(4)$ & $\operatorname{Col}(5)$ & $\operatorname{Col}(6)$ & $\operatorname{Col}(7)$ & $\operatorname{Col}(8)$ \\
\hline & $\mu_{\Delta \mathrm{F} 1}$ & $\sigma_{\Delta \mathrm{F} 1}$ & Skewness & Kurtosis & $\mu_{\Delta(\mathrm{F} 2-\mathrm{F} 1)}$ & $\sigma_{\Delta(\mathrm{F} 2-\mathrm{F} 1)}$ & Skewness & Kurtosis \\
\hline \multicolumn{9}{|c|}{ Crude Oil (cl) } \\
\hline 1991 & -.04 & .66 & -.56 & 1.40 & .220 & 1.25 & .23 & 1.62 \\
\hline 1992 & -.01 & .25 & -.24 & 1.06 & .023 & .30 & .11 & 1.10 \\
\hline 1993 & -.02 & .23 & .24 & .42 & .032 & .32 & -.11 & .37 \\
\hline 1994 & .01 & .29 & -.10 & .58 & -.045 & .46 & .13 & .02 \\
\hline 1995 & .01 & .21 & -.28 & 1.04 & -.008 & .31 & -.06 & .26 \\
\hline 1996 & .05 & .36 & .06 & .67 & -.010 & .51 & .27 & 1.50 \\
\hline 1997 & -.00 & .37 & -.01 & .01 & .045 & .51 & -.02 & .95 \\
\hline $91-97$ & -.00 & .34 & -.13 & .74 & .037 & .52 & .08 & .83 \\
\hline \multicolumn{9}{|c|}{ Corn $(\mathrm{cn})$} \\
\hline 1991 & -.09 & 2.70 & -.17 & .24 & .02 & 3.20 & -.47 & 1.80 \\
\hline 1992 & -.27 & 2.45 & -.47 & 1.40 & -.13 & 3.00 & .14 & .43 \\
\hline 1993 & .10 & 2.13 & .43 & 1.26 & .00 & 2.60 & -.08 & 1.34 \\
\hline 1994 & -.37 & 2.97 & -.69 & 2.11 & .02 & 4.03 & -.42 & 4.59 \\
\hline 1995 & .35 & 2.35 & -.10 & .94 & -.02 & 2.71 & .22 & .45 \\
\hline 1996 & .48 & 6.51 & -.49 & 2.02 & -.31 & 9.38 & .11 & 6.52 \\
\hline 1997 & .00 & 3.82 & .08 & .34 & .11 & 4.22 & .11 & 1.40 \\
\hline $91-97$ & .03 & 3.28 & -.20 & 1.19 & -.04 & 4.16 & -.06 & 2.36 \\
\hline \multicolumn{9}{|c|}{ Deutschemark (dm) } \\
\hline 1991 & -.00015 & .0053 & .20 & 1.49 & -.00150 & .0096 & -.01 & 12.15 \\
\hline 1992 & .00018 & .0053 & -.37 & 1.12 & -.00072 & .0100 & .32 & 15.12 \\
\hline 1993 & -.00008 & .0043 & .07 & .45 & -.00100 & .0072 & -1.21 & 7.72 \\
\hline 1994 & .00024 & .0037 & -.10 & 1.37 & .00043 & .0046 & .75 & 4.47 \\
\hline 1995 & .00019 & .0054 & .18 & 3.21 & .00100 & .0063 & .84 & 3.76 \\
\hline 1996 & -.00021 & .0028 & .39 & 2.67 & .00048 & 0087 & 1.47 & 22.68 \\
\hline 1997 & -.00039 & .0036 & -.01 & .14 & .00110 & .0100 & 3.14 & 20.27 \\
\hline $91-97$ & -.00003 & .0043 & .05 & 1.49 & -.00003 & .0081 & .76 & 12.31 \\
\hline \multicolumn{9}{|c|}{ Eurodollar (ed) } \\
\hline 1991 & .0130 & .055 & .37 & 1.76 & .0064 & .078 & .34 & 1.12 \\
\hline 1992 & .0054 & .061 & 1.29 & 7.54 & .0100 & .080 & -.14 & 1.29 \\
\hline 1993 & .0045 & .033 & -.41 & 4.58 & .0099 & .063 & .19 & 2.93 \\
\hline 1994 & -.0037 & .045 & -.00 & 2.66 & .0053 & .093 & .86 & 2.74 \\
\hline 1995 & .0045 & .049 & .55 & 2.78 & .0110 & .090 & .50 & 3.01 \\
\hline 1996 & .0011 & .030 & -.31 & 4.68 & -.0001 & .021 & .18 & 1.00 \\
\hline 1997 & .0001 & .018 & .64 & 3.86 & .0009 & .014 & -.02 & 1.27 \\
\hline 91-97 & .0025 & .035 & .26 & 4.08 & .0041 & .046 & .20 & 1.63 \\
\hline \multicolumn{9}{|c|}{ Gold $(\mathrm{gc})$} \\
\hline 1991 & -.14 & 2.76 & -.23 & 3.44 & -.86 & 6.57 & -1.07 & 8.15 \\
\hline 1992 & -.19 & 1.85 & -.16 & 1.48 & -.34 & 3.52 & -.03 & 2.34 \\
\hline 1993 & .11 & 2.97 & -.09 & 2.03 & .82 & 5.17 & .49 & 2.50 \\
\hline 1994 & -.03 & 2.34 & .04 & 1.28 & -.58 & 7.72 & -1.63 & 7.62 \\
\hline 1995 & -.03 & 1.53 & -.37 & 1.83 & -1.54 & 7.49 & -.58 & 12.11 \\
\hline 1996 & -.12 & 1.37 & -.12 & .24 & -.51 & 4.40 & -.34 & 13.79 \\
\hline 1997 & -.33 & 2.31 & -.22 & 1.02 & -1.27 & 6.11 & .06 & 11.92 \\
\hline $91-97$ & -.12 & 2.04 & -.18 & 1.43 & -.75 & 5.87 & -.39 & 9.58 \\
\hline
\end{tabular}




\section{E X H I B I T 4 (continued)}

Distributional Properties for One Outright versus VaR-Adjusted Calendar Spread

\begin{tabular}{|c|c|c|c|c|c|c|c|c|}
\hline & $\mu_{\Delta \mathrm{F} 1}$ & $\sigma_{\Delta} \mathrm{F} 1$ & Skewness & Kurtosis & $\mu_{\Delta(\mathrm{F} 2-\mathrm{F} 1)}$ & $\sigma_{\Delta}(\mathrm{F} 2-\mathrm{F} 1)$ & Skewness & Kurtosis \\
\hline \multicolumn{9}{|c|}{ Live Cattle (lc) } \\
\hline 1991 & .006 & .46 & -.01 & .46 & .020 & .50 & .38 & .19 \\
\hline 1992 & .040 & .48 & -.07 & .18 & .033 & .50 & -.39 & -.23 \\
\hline 1993 & .021 & .48 & .06 & .08 & .002 & .50 & -.13 & .42 \\
\hline 1994 & -.034 & .58 & .02 & .23 & .030 & .65 & -.32 & 1.86 \\
\hline 1995 & .015 & .56 & .16 & .23 & .011 & .62 & -.13 & -.17 \\
\hline 1996 & -.002 & .59 & .13 & -.12 & .032 & .64 & -.25 & .10 \\
\hline 1997 & .011 & .50 & -.17 & .20 & -.028 & .56 & .23 & .86 \\
\hline $91-97$ & .008 & .52 & .02 & .18 & .014 & .57 & -.09 & .43 \\
\hline \multicolumn{9}{|c|}{ Natural Gas (ng) } \\
\hline 1991 & -.0038 & .023 & -.22 & .64 & .0038 & .025 & -.13 & 1.47 \\
\hline 1992 & .0025 & .036 & .01 & .73 & -.0047 & .040 & -.03 & .37 \\
\hline 1993 & .0013 & .042 & -.40 & .95 & -.0011 & .057 & .19 & 1.74 \\
\hline 1994 & -.0030 & .038 & .16 & -.33 & .0029 & .049 & -.11 & .05 \\
\hline 1995 & -.0032 & .035 & .02 & .52 & -.0000 & .054 & -.32 & 2.17 \\
\hline 1996 & .0067 & .069 & -.01 & .20 & -.0038 & .085 & .08 & .86 \\
\hline 1997 & .0048 & .087 & -.03 & .67 & .0005 & .120 & -.41 & 1.91 \\
\hline $91-97$ & .0007 & .047 & -.07 & .49 & -.0003 & .060 & -.11 & 1.23 \\
\hline \multicolumn{9}{|c|}{ S\&P 500 (sp) } \\
\hline 1991 & .16 & 3.35 & .03 & 2.67 & .98 & 4.46 & 2.45 & 9.09 \\
\hline 1992 & .20 & 2.76 & .25 & .91 & .32 & 3.11 & 3.51 & 25.68 \\
\hline 1993 & .11 & 2.47 & -.02 & 1.86 & .19 & 2.26 & .32 & .87 \\
\hline 1994 & -.06 & 2.98 & -.54 & 2.44 & .64 & 3.35 & 1.71 & 7.04 \\
\hline 1995 & .54 & 2.76 & -.04 & .79 & 1.44 & 6.45 & 1.84 & 8.85 \\
\hline 1996 & .51 & 5.16 & -.50 & 1.24 & 1.62 & 11.50 & 2.70 & 19.36 \\
\hline 1997 & .65 & 10.76 & -.47 & 1.96 & 3.81 & 20.85 & 3.66 & 20.46 \\
\hline $91-97$ & .30 & 4.32 & -.19 & 1.70 & 1.29 & 7.43 & 2.31 & 13.05 \\
\hline \multicolumn{9}{|c|}{ Soybeans (sy) } \\
\hline 1991 & -.25 & 8.29 & -.38 & 1.24 & .30 & 9.72 & .21 & 2.12 \\
\hline 1992 & -.26 & 5.31 & -.34 & .62 & -.74 & 7.13 & .04 & .10 \\
\hline 1993 & .19 & 6.56 & -.12 & .84 & .30 & 7.22 & .23 & 1.62 \\
\hline 1994 & -.50 & 7.43 & -.05 & 3.21 & .45 & 9.98 & .10 & 1.08 \\
\hline 1995 & .32 & 5.86 & -.02 & 1.39 & .45 & 6.73 & .83 & 2.97 \\
\hline 1996 & .20 & 9.49 & -.13 & .29 & -.70 & 10.78 & .02 & .19 \\
\hline 1997 & .77 & 10.78 & -.01 & .51 & -.57 & 12.24 & -.30 & .12 \\
\hline $91-97$ & .07 & 7.68 & -.15 & 1.16 & -.07 & 9.11 & .16 & 1.17 \\
\hline \multicolumn{9}{|c|}{ U.S. Treasury Bond (us) } \\
\hline 1991 & .029 & .52 & .23 & 1.04 & -.037 & .86 & .53 & 4.15 \\
\hline 1992 & .030 & .50 & -.05 & .28 & .004 & 1.06 & .32 & 5.23 \\
\hline 1993 & .069 & .56 & .19 & .38 & -.081 & 1.33 & -.71 & 7.65 \\
\hline 1994 & -.050 & .68 & .00 & .34 & .036 & 1.06 & -.19 & 3.70 \\
\hline 1995 & .091 & .59 & .30 & .41 & .042 & .78 & .41 & 3.82 \\
\hline 1996 & -.057 & .72 & -.81 & 2.11 & -.150 & 1.17 & -1.84 & 7.68 \\
\hline 1997 & .048 & .53 & -.09 & 1.75 & .100 & .81 & .40 & 4.92 \\
\hline 91-97 & .026 & .58 & -.00 & .86 & -.008 & 1.00 & -.09 & 5.22 \\
\hline
\end{tabular}

Columns (1) through (4) provide the mean, standard deviation, skewness, and kurtosis of daily price changes in one outright futures contract, averaged over all contract periods that expire within each calendar year. Columns (5) through (8) provide the mean, standard deviation, skewness, and kurtosis of daily price changes in a VaR-adjusted calendar spread, averaged over all contract periods that expire within each calendar year. 


\section{E X H I B I T 5}

\section{Normality Tests for Daily Price Changes in One Outright Futures Contract and VaR-Adjusted Spread}

\begin{tabular}{|c|c|c|c|c|c|c|c|}
\hline \multirow{3}{*}{ Contract } & & \multicolumn{3}{|c|}{ Outright } & \multicolumn{3}{|c|}{ VaR-adjusted Spread } \\
\hline & \# of tests & \multicolumn{3}{|c|}{$\begin{array}{c}\text { relative frequency } \\
\text { of rejecting normality } \\
\text { hypothesis } \\
\text { (level of significance) }\end{array}$} & \multicolumn{3}{|c|}{$\begin{array}{c}\text { relative frequency } \\
\text { of rejecting normality } \\
\text { hypothesis } \\
\text { (level of significance) }\end{array}$} \\
\hline & & $(.10$ & $(.05)$ & $(.01)$ & $(.10)$ & $(.05)$ & $(.01)$ \\
\hline crude oil (cl) & 84 & .23 & .18 & .02 & 20 & .14 & .06 \\
\hline $\operatorname{corn}(\mathrm{cn})$ & 36 & .29 & .17 & .09 & .46 & .34 & .20 \\
\hline Deutschemarks (dm) & 28 & .21 & .18 & .14 & 1.00 & 1.00 & 1.00 \\
\hline Eurodollar (ed) & 44 & .86 & .73 & .64 & .75 & .64 & .48 \\
\hline gold (gc) & 60 & .29 & .22 & .09 & 1.00 & 1.00 & .97 \\
\hline live cattle (lc) & 42 & .07 & .05 & 0 & .19 & .14 & .12 \\
\hline natural gas (ng) & 84 & .17 & .10 & .05 & .30 & .24 & .16 \\
\hline S\&P $500(\mathrm{sp})$ & 28 & .36 & .25 & .14 & .89 & .89 & .82 \\
\hline soybeans (sy) & 50 & .33 & .20 & .12 & .37 & .27 & .16 \\
\hline U.S. bonds (us) & 28 & .26 & .15 & 0 & 1.00 & 1.00 & 1.00 \\
\hline
\end{tabular}

These results represent the relative frequencies of rejecting the null hypothesis that each series of daily price changes is normally distributed, for all contract periods from 1991-97.

VaR-adjusted spread revealing greater kurtosis by an average multiple in excess of 6 . For these four contracts, the profit or loss associated with a VaR-adjusted spread is likely to be larger than that associated with an outright position, in times of extreme market stress.

In light of this behavior, we formally test the hypothesis that daily price changes for each position (a single outright futures and the VaR-adjusted spread) are normally distributed, for all 10 contracts, over each contract period. Results are provided in Exhibit 5, and are consistent with the evidence presented in Exhibit 4. Keep in mind that kurtosis $=3$ for the normal distribution. In this light, the four contracts that display substantially greater kurtosis for the VaR-adjusted spread position (i.e., Deutschemarks, gold, S\&P 500, and U.S. bonds) also display substantially higher rejection frequencies for the VaRadjusted spread position than for outright futures. The remaining six contracts display similar rejection frequencies across the two positions.

\section{Simulations of Trading Rules for Outright and VaR-Adjusted Spread}

Simulation results are presented for all 10 contracts in Exhibits 6-15. These simulations impose a trading rule that stipulates entering a long position in a single out- right futures (or VaR-adjusted spread) if a 20-day moving average of past futures (or spread) prices increases, and entering a short position if the moving average declines. Exhibits 6-15 plot the ex post performance of this trading rule for all business days from 1995-1997. These exhibits thus display the relative risks and rewards of this ex ante trading strategy for a single futures versus a VaR-adjusted spread.

Consistent with the ex post relative risks revealed in Exhibit 4, Exhibits 6-15 clearly indicate that, for most contracts, trading VaR-adjusted spreads results in higher volatility than trading outright futures. Despite the higher volatility, however, the VaR-adjusted spread strategy realizes higher returns over this simulation period for just five of the 10 contracts.

Importantly, the results provided in Exhibits 6-15 do not adjust for the relative transactions costs or capital requirements incurred for each trading strategy. When these adjustments are made, the VaR-adjusted spread trading strategy experiences substantially worse performance for all 10 contracts, due to both the higher transactions costs and higher capitalization requirements associated with trading VaR-adjusted spreads. This outcome reinforces the conclusion that trading VaR-adjusted spreads leads to lower risk-adjusted returns than trading outright futures. 


\section{E X H I B I T 6}

20-Day MA Results for CL

$\mathbf{P} / \mathbf{L}$

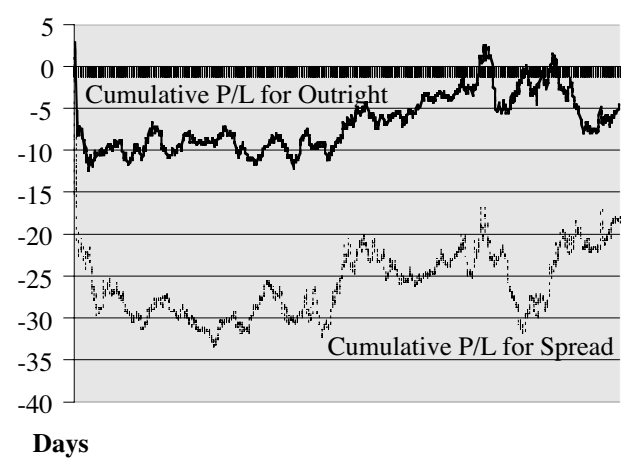

\section{E X H I B I T 7}

20-Day MA Results for CN

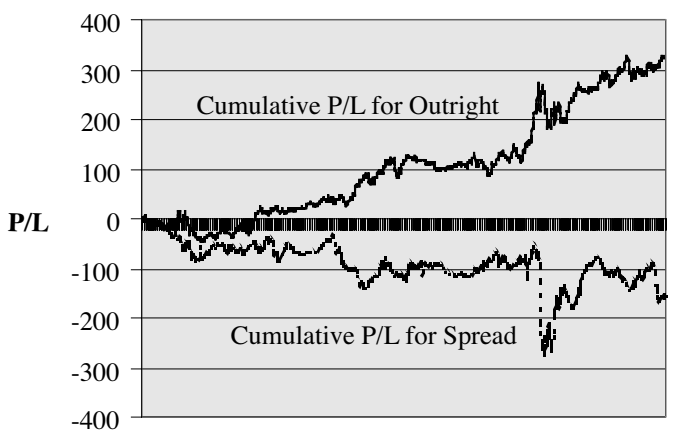

Days
EX нів I T 9

20-Day MA Results for ED

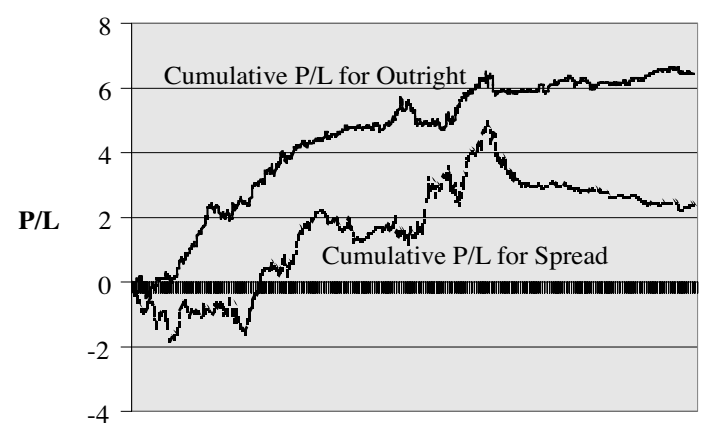

Days
E X H I B I T 10

20-Day MA Results for GC

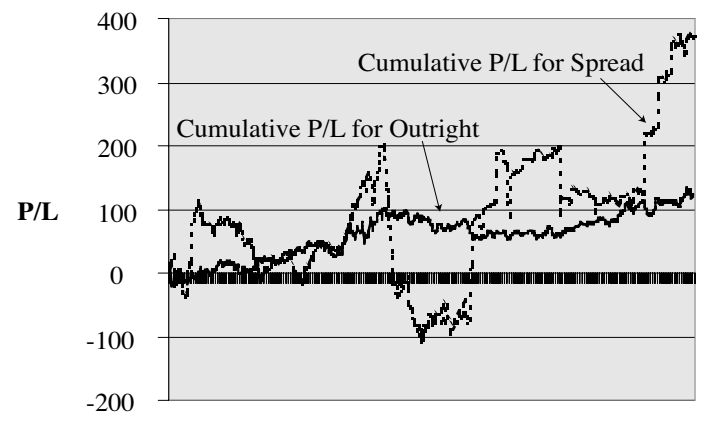

Days

\section{E X H I B I T 8}

20-Day MA Results for DM

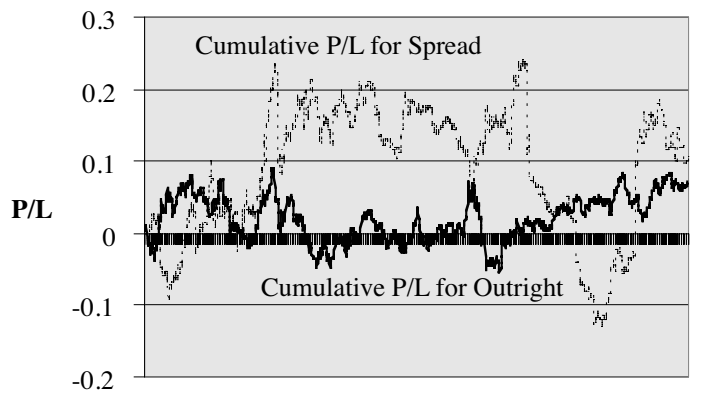

Days
E X H I B I T 11

20-Day MA Results for LC

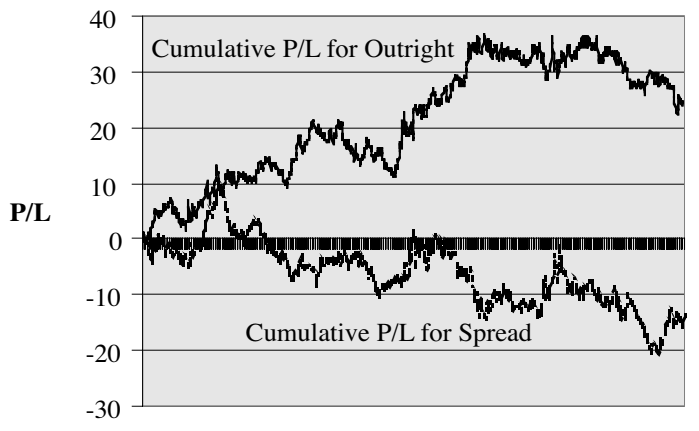

Days 


\section{E X H I B I T 12}

20-Day MA Results for NG

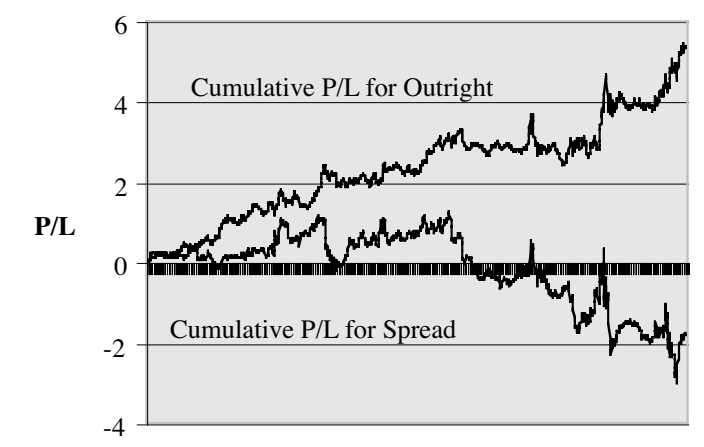

Days

\section{E X H I B I T 13}

20-Day MA Results for SP

$\mathbf{P} / \mathbf{L}$

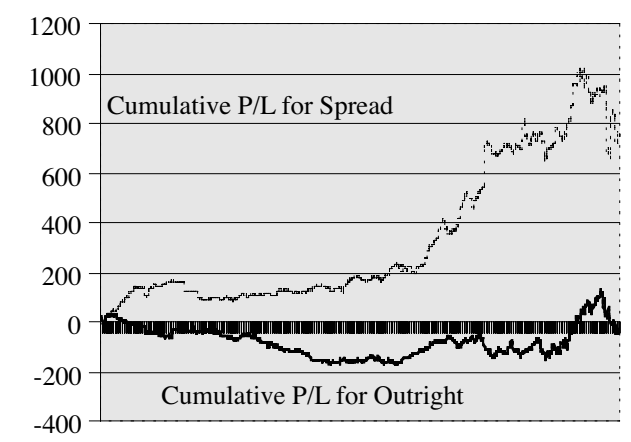

Days

E X H I B I T $\mathbf{1 4}$

20-Day MA Results for SY

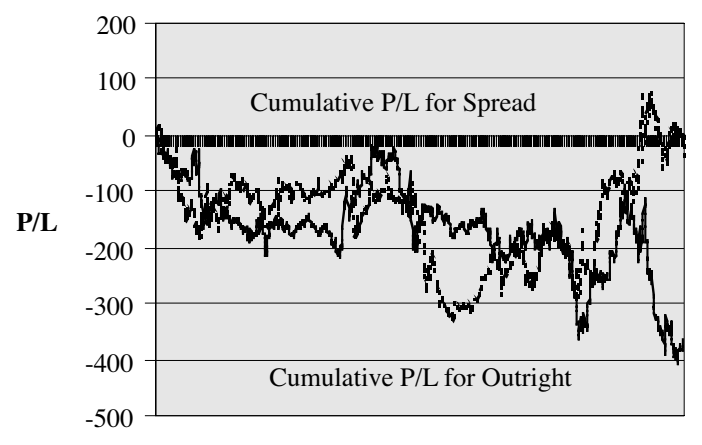

Days

\section{E X H I B I T 15 \\ 20-Day MA Results for US}

$\mathbf{P} / \mathbf{L}$

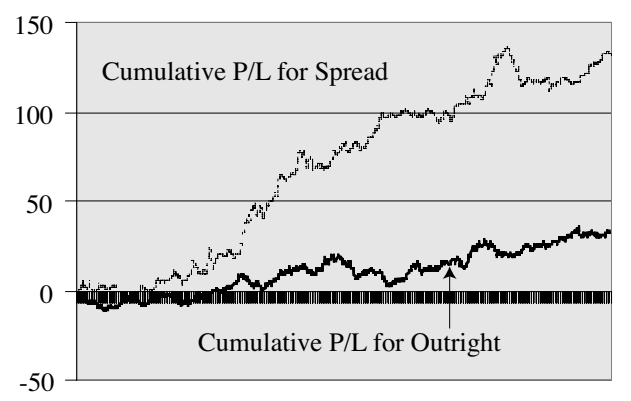

Days

\section{SUMMARY AND CONCLUSIONS}

This study examines the relative risks and rewards of trading: 1) a single outright futures contract, 2) a single calendar spread, and 3) a multiple of calendar spreads that yields the same ex ante value-at-risk as a single outright (labeled the VaR-adjusted spread).

Our first area of investigation probes the question of whether calendar spreads might reasonably be used as surrogate trades for outright futures contracts. Given the low and unstable correlation that is generally found between calendar spread prices and outright futures, we conclude that this orientation is not promising. Instead, including spreads in a portfolio could provide risk-reduction benefits associated with diversification.

Second, as expected, the analysis demonstrates that a single outright futures contract exhibits a substantial multiple over a single calendar spread position in terms of both mean daily price changes and the volatility of price changes. However, this volatility is unstable across contract periods for both outright futures and calendar spread price changes. The ratio of these two volatilities $\left(\sigma_{\Delta \mathrm{F} 1} / \sigma_{\Delta(\mathrm{F} 2-\mathrm{F} 1)}\right)$ is also unstable, suggesting that substantial adjustments would be required to maintain a VaRadjusted spread position over time.

The analysis also sheds light on the relative ex post performance of spread trading strategies versus outright futures trading, and on the validity of normality assumptions made to motivate and generate these strategies. Our findings challenge the notion that spread trading is less risky than outright futures trading in that the VaR-adjusted spreads often experience greater volatility than outright futures, in the form of higher standard deviations and kurtosis, ex post. This relatively high volatility for VaR- 
adjusted spread prices vis-à-vis outright futures prices may justify the seemingly high initial margin requirements for calendar spreads relative to outright futures, when based on the ex ante volatility ratios. As a result of this relatively high volatility, the VaR-adjusted spread strategy experiences lower risk-adjusted returns than trading outright futures.Consideration of transactions costs and capital requirements reinforces these conclusions. These results should be of particular interest to regulators, the exchanges through which these markets operate, and traders seeking to maximize expected risk-adjusted returns in these markets.

\section{ENDNOTES}

${ }^{1}$ This conclusion would be true only in an ex post sense. Ex ante we "control for equal VaR." Thus, any empirical differences should reflect which strategy, the outright futures or VaR-adjusted spread, is more volatile over time.

${ }^{2}$ This expectation might not be realized, however, if outright prices exhibit more trend reversals than spread prices.

${ }^{3}$ Of course, many managers retain the flexibility to override these objective signals as conditions warrant.

${ }^{4}$ If a spread is constructed with roughly equivalent exposures on the long and short sides, it is said to be market-neutral. Consistent with prior work, all spreads are constructed here using long and short market-neutral futures positions. See, for example, Billingsley and Chance [1988], Castelino and Vora [1984], Cuny [2002], Kim and Leuthold [1997], and Poitras [1990].

${ }^{5}$ See Cornew et al. [1984] and Hudson et al. [1987] for examples of studies that examine the empirical distribution of daily changes in futures prices, and investigate departures from normality.

${ }^{6} \mathrm{We}$ address this complication in our analysis by re-estimating the ratio of standard deviations, and rebalancing the VaR-adjusted spread position, over two time frames-on both a daily and a weekly basis. Overall results are similar, leading us to present results only for weekly rebalancing. It is noteworthy, however, that daily rebalancing leads to somewhat greater instability in the VaR-adjusted spread (higher standard deviations, skewness, and kurtosis) relative to weekly rebalancing, consistent with this concern.

${ }^{7} \mathrm{We}$ cannot compute daily returns using first log differences of the spread series, $\left(\mathrm{F}_{2}-\mathrm{F}_{1}\right)$, because the spread will be zero or negative if the forward curve is flat or backwardated. Likewise, it is inappropriate to compute daily percent changes in the spread price directly, since this would involve dividing by a number close to zero when the forward curve is flat. Hence we perform the analysis on daily changes in both the outright and spread price series. This approach is consistent with prior research (Cornew et al. [1984]; Hudson et al. [1987]; Kim and Leuthold [1997]; Poitras [1990]).
${ }^{8}$ One popular non-parametric method chooses the optimal bandwidth to describe the data as generated from a mixed-normal distribution (Butler and Schachter [1996]). The bootstrap method repeatedly generates new random samples from the data available, and calculates quantiles from the collection of new samples. For more on this issue, see Beder [1995], Hendricks [1995], Hull and White [1998], Kim and Leuthold [1997], Kupiec [1996], Li [1999], Mahoney [1995], and Pritzker [1995].

${ }^{9}$ We limit our analysis to the regular expiration cycle, and exclude serial expirations.

${ }^{10}$ The use of the terms "long spread" or "short spread" on the Street is not consistent across markets. That is, in some markets a long spread refers to buying the nearby contract and selling the deferred, while in other markets the trades are reversed. Regardless of the way traders label the transaction, when $\left(\mathrm{F}_{2}-\mathrm{F}_{1}\right)$ increases, in this simulation we buy the deferred contract and sell the nearby, and vice versa when $\left(F_{2}-F_{1}\right)$ decreases.

${ }^{11} \mathrm{We}$ have simulated these trading rules with and without adjustment for: 1) transactions costs, and 2) the relative capital requirements documented in Exhibit 1. Without these adjustments, the two trading strategies experience similar returns. When these adjustments are made, however, the VaR-adjusted spread performs substantially worse. For brevity, we present only the results without adjustment for transactions costs or capital requirements. All results are available upon request.

${ }^{12}$ Note that the correlation $\rho_{\mathrm{F} 1,(\mathrm{~F} 2-\mathrm{F} 1)}=\left[\operatorname{Cov}\left(\mathrm{F}_{1}, \mathrm{~F}_{2}\right)-\right.$ $\left.\sigma_{\mathrm{F} 1}^{2}\right] /\left(\sigma_{\mathrm{F} 1} \sigma_{(\mathrm{F} 2-\mathrm{F} 1)}\right)$, is negative if $\operatorname{Cov}\left(\mathrm{F}_{1}, \mathrm{~F}_{2}\right)<\sigma^{2}\left(\mathrm{~F}_{1}\right)$.

${ }^{13}$ The VaR-adjusted spread displays a smaller standard deviation for just two annual subsamples with Eurodollar futures, and for just one annual subsample with S\&P 500 futures. For all other annual subsamples and all contracts investigated, the VaR-adjusted spread experiences greater volatility than the outright position.

${ }^{14}$ While the S\&P 500 outright futures contract displays little skewness, the VaR-adjusted spread on this contract experiences substantial positive skewness.

\section{REFERENCES}

Beder, T. "VaR: Seductive but Dangerous." Financial Analysts Journal, September/October 1995, pp. 12-24.

Billingsley, R.S., and D.M. Chance. "The Pricing and Performance of Stock Index Futures Spreads." Journal of Futures Markets, 8 (1988), pp. 303-318.

Brorsen, B.W., and L.P. Lukac. "Optimal Portfolios for Commodity Futures Funds.” Journal of Futures Markets, 10 (1990), pp. 247-258. 
Butler, J.S., and B. Schachter. "Improving Value-at-Risk Estimates by Combining Kernel Estimation with Historical Simulation." Unpublished manuscript, Comptroller of the Currency, 1996.

Castelino, M.G., and A. Vora. "Spread Volatility in Commodity Futures: The Length Effect." Journal of Futures Markets, 4 (1984), pp. 39-46.

Cornew, R.W., D.E. Town, and L.D. Crowson. "Stable Distributions, Futures Price, and the Measurement of Trading Performance." Journal of Futures Markets, 4 (1984), pp. 531-557.

Cuny, Charles J. "Spread Futures: Why Derivatives on Derivatives?" Working paper, Texas A\&M, 2002.

Dutt, H.R., J. Fenton, J.D. Smith, and G.H.K. Wang. “Crop Year Influences and Variability of the Agricultural Futures Spreads." Journal of Futures Markets, 17 (1997), pp. 341-367.

Edwards, F.R., and J. Liew. "Managed Commodity Funds." Journal of Futures Markets, 19 (1999), pp. 377-412.

Hall, J.A., B.W. Brorsen, and S.H. Irwin. "The Distribution of Futures Prices: A Test of the Stable Paretian and Mixture of Normals Hypothesis." Journal of Financial and Quantitative Analysis, 24 (1989), pp. 105-116.

Hendricks, D. "Evaluating Value-at-Risk Models Using Historical Data." Unpublished manuscript, Federal Reserve Bank of New York, July 1995.

Hudson, M.A., R.M. Leuthold, and G.F. Sarassoro. "Commodity Futures Price Changes: Recent Evidence for Wheat, Soybeans, and Live Cattle." Journal of Futures Markets, 7 (1987), pp. 287-301.

Hull, J.C. Fundamentals of Futures and Options Markets. 4th ed. Englewood Cliffs, NJ: Prentice-Hall, 2002.

Hull, J., and A. White. "Value at Risk When Daily Changes in Market Variables Are Not Normally Distributed." The Journal of Derivatives, Vol. 5, No. 3 (1998), pp. 9-19.
Jorion, Philippe. Value at Risk. New York, NY: McGraw-Hill, 1997.

Kim, M.K., and R.M. Leuthold. "The Distributional Behavior of Futures Price Spread Changes: Parametric and Nonparametric Tests for Gold, T-Bonds, Corn, and Live Cattle." Unpublished manuscript, OFOR Working Paper \#97-03, 1997.

Kupiec, P. "Techniques for Verifying the Accuracy of Risk Measurement Models." The Journal of Derivatives, Vol. 3, No. 2 (1995), pp. 73-84.

Li, D.X. "Value at Risk Based on Volatility, Skewness and Kurtosis.” Unpublished manuscript, RiskMetrics Group, 1999.

Mahoney, J. “Empirical-Based versus Model-Based Approaches to Value-at-Risk." Unpublished manuscript, Federal Reserve Bank of New York, September 1995.

Poitras, G.N. "The Distribution of Gold Futures Spreads." Journal of Futures Markets, 10 (1990), pp. 643-659.

—. "Spread Options, Exchange Options, and Arithmetic Brownian Motion." Journal of Futures Markets, 18 (1998), pp. 487-517.

Pritzker, M. "Evaluating Value-at-Risk Methodologies: Accuracy versus Computational Time." Unpublished manuscript, Board of Governors of the Federal Reserve, November 1995

Schneeweis, T., R. Spurgin, and D. McCarthy. "Survivor Bias in Commodity Trading Advisor Performance." Journal of Futures Markets, 16 (1996), pp. 757-772.

To order reprints of this article, please contact Ajani Malik at amalik@iijournals.com or 212-224-3205. 